modined extremity of the neurilemma of the nervous tubules which enter the papilla ;"--differing from the Paccinian corpuscles (which I shall describe in my next lecture), in that the neurilemma in the latter is developed on both sides of the nerve-filament, while in the former-that is, in the corpusculum tactus-it is only developed on one side. He further thinks there is the clearest possible reason to believe that the nerve-fibrils have free terminations in the corpuseles, or, in other words, become continuous with the connective tissue of the papilla through the corpuscle, in a similar manner to which he has seen them terminate in the papilla of the tongue of the frog, which was first noticed by Waller. He has not, however, succeeded in demonstrating this in man. Although this view of the morphological nature of the corpuscula tactûs is not inconsistent with what appears to occur elsewhere, yet it cannot be borne out by exact observation. The identity of the corpuscle with the somewhat dense and defined axillary portion of the papille as deseribed by Kolliker is suggested by the preparations I have been successful in making; but the nervefibrils, though obscure and not readily followed, appeared to me to terminate in, or perhaps upon, the corpuscle. I have now sufficiently discussed the somewhat dubious structural characters of these minute bodies; let us next attend for a little to their claims as reputed organs of touch.

In accordance with the elaborate structure which Wagner and Meissner originally described these bodies as possessing, their action was believed to be like that of elastic cushions, which intensified the impressions received by them, and conducted to the nerve-fibrils lying imbedded in their substance as well as coiled around them. In this way, they were enabled to communicate sensations of pressure, and, as Weber supposed, by the expansion or contraction produced in them by changes of temperature, they were enabled to appreciate the various degrees of heat and cold. Wagner* has, in relation to the functions of these bodies, accounted for the fact that the vascular exceed in length or elevation from the cutaneous surface the corpusculated papilla, and he does so by advancing the theory of an abundant supply of warm blood in the immediate neighbourhood of the sensitive papilla being necessary to prevent the sense of touch from being impaired by the temperature of the nervous structures within them being more or less permanently lowered by sudden contact with bodies of a less elevated temperature. He points to a parallelism in this respect apparent in the position of the retina, the nervous structure appended to the optic nerve-fibres, which is bounded by the highly vascular choroid, similar provision being also made in the peripheral expansion of the auditory nerve and other special sensory structures, - a certain elevation of temperature being apparently necessary to be maintained, in order to the sustained exercise of the functions of the nerves of special sense. Kölliker, judging from his own views as to the simplicity of their structure, and the circnmstance of all the essential sensory functions of the skin existing where he was unable to find them, regards them as bodies " which, in consequence of their being composed of dense, imperfectly-formed elastic tissue, confer a certain amount of solidity upon the points of the papillæ, and serve as a firm support for the nerves, in consequence of which a pressure which in other situations is not sufficient to affect here takes effect;" and he believes them in this manner to have no more special influence on the nerves of touch than the phalanges and nails are known to possess.

Dr. Franz Leydig, in a recent memoir, classes together the Paccinian corpuscles, the Savian bodies of the torpedo, and the so-called muciparous cancls of the osseous and cartilaginous fishes as homologous organs. Huxley, following up this idea, and viewing the corpusculum tactos as an elaboration of the neurilemma, as he also views the Paccinian corpuscles, places the former at the bottom of Leydig's series; and tracing an analogy between the muciparous canals and the follicles in which the vibrissæ (which are found on the lips and eyebrows of nearly all mammalia) are produced, places them at the top of the same series of cutaneous organs of sensibility, the lowest member of which, as I have said, he regards the corpusculum tactus to form. Admitting the possibility of such a graduated relationship subsisting between the different organs I have just mentioned, it must be confessed that the evidence yet adduced in support of it does not seem to me to warrant so positive and direct a conclusion. The identity of all the organs in question with the sense of touch is far from being generally admitted. While agreeing with Professor Huxley as to perhaps a more than general resemblance between the members ôt his group, I can in the meantime only view them, from their apparent * Neurol. Untersuch, p. 137 anatomical relations, as organs developed in certain parts of the periphery, on nerves not all cutaneous, to subserve some particular, and it may be, so far as we can speak positively, some very opposite function. But that the corpuscula tactûs are special structures having a definite relation to the nerves of the sense of tonch-in fact, that they are developed in connexion with the papille and the poripheral extremities of the nerves of touch, and constituting with them the special organ of that sense, I believe there can be to doubt. They are probably a modified development of the neurilemma in and upon which the sensory fibrils terminate, and they subserve the function of touch by placing them under highly favourable conditions for receiving the most delicate impressions, by means of their continuity with a highly elastic body.

At our next meeting, I shall describe to you the Paccinian corpuscles concluding the sensory structures in the skin, and also the gustatory apparatus in the tongue.

\section{NEW TESTS FOR THE KIESTEINE OF PREGNANCY.}

BY J. BRAXTON HICKS, M.D. LOND., F.L.S., \&c. assistant PEXSICLAN-ACCODCHEUR to GUY's hosptTAL.

THE time consumed by the usual method of obtaining kiesteine, and the unpleasant odour arising from its decomposition, render it a desideratum to possess a test, which shall hasten its appearance, and increase the quantity deposited from the urine. Into the value of it as a sign of pregnancy, I do not intend at present to enter; but as a readier means of ascertaining its existence will assist investigations on that point, I beg to offer my experience on the action of rennet on urine containing the above-named substance. What the composition of this substance is, as it exists in newly-passed urine, has not been as yet ascertained. There can be scarcely any doubt that the action of the air alters it into a substance very similar to casein, if not identical with it, inasmuch as it is coagulable by rennet, and insoluble in cold acetic acid, and generally by hot. That the substance called by Dr. Stark "gravidine" is another substance seems probable, and may be that which is precipitated out of some urine of pregnancy by a small quantity of acetic acid, though it is generally re-dissolved in from six to twenty hours; or it may be the same substance in varying degrees of alteration. The readiness with which this change takes place, whatever it may be, varies very considerably in pregnant women, and that without any apparent cause. A few hours' exposure to or agitation with air is sufficient to deposit the altered substance; while in others, two days are required: and this is not altogether dependent on the period of pregnancy; for I have found a person, only four months and a half advanced, yield copious deposit in three hours after passing; while another, at the full term, required within two or three days.

Now, as there is no amorphous deposit thrown down from urine previonsly clear, within two or three days, which is not easily dissolved by heat (lithates) or by dilute acetic acid (phosphates and carbonates), excepting from that of pregnant women, it is evidently not necessary to wait till the decomposition has gone on to form the white pellicle which ensues upon protracted exposure; but if a deposit takes place varying in colour according to that of the urine (but naturally white), unchanged by the above-named tests, then we may safely conclude that the urine contains kiesteine.

This deposit varies from copious troubling to that of small flakes falling to the bottom, and probably results from the natural acid of the urine, or the formation of lactic acid in it, coagulating the newly-altered kiesteine; and the time at which the troubling takes place varies also, probably, with the rapidity with which the change by the air goes on and the condition of acidity.

If, then, we add rennet to urine of pregnancy, we shall find that in nearly every case the deposit above alluded to appears at an earlier date than if it is not employed : in some cases, within an hour (this is uncommon); in others (especially if the urine be recently passed), in from twelve to twenty-four hours. In the majority of instances, the change produced by the abovenamed agent has been in advance of the usual method by about half the time, and the quantity of the deposit has been decidedly greater. 
Now, the greasy-looking pellicle which has always been waited for as a sure sign of kiesteine, consists of a small quantity of amorphons matter (kiesteine); occasionally a few fatglobules, but not constant; numerous crystals of the tripophosphate, amorphous carbonate, and phosphate of lime, which incrusts the numerous so-called vibriones, thereby preventing their peculiar movements till released by the addition of acetio or other acid. All these are produced by the process of decomposition, and form therefore but a crude test, being also somewhat imitated by the decomposition of albuminous and diabetic urine.

Rennet, I have found, has no action on healthy, diabetic, albuminous, or phosphatic urine. A slight deposit sometimes rakes place, looking something like mucus; but I think urine giving off but a slight precipitate should be held doubtful in respect of kiesteine.

If, after the deposit is well formed, we add to say half an ounce of the turbid urine (taking the lower portions) a few drops of strong solution of ammonia, and boil for a minute or two, we shall find the deposit is formed into a semi-mucons mass, so that the urine becomes almost tremulous. When this occurs, it is, I think, characteristic of kiesteine. It can be produced without boiling, but the change is slower and not so complete. If the deposit be scanty, the above appearance is not so well marked; but, by careful watching, it may be observed. amongst the flakes which are formed.

This test for kiesteine can be employed equally well with or without the previous use of rennet. The quantity of phosphates thrown down by the ammonia may be known by adding gradually acetic acid, so as to slightly acidulate. What remains undissolved is the kiesteine.

In employing rennet, I find the best method is to mix about two teaspoonfuls (as described below) with about three ounces of the urine, if it be recently passed; but if it has stood some time, and the kiesteine is about to be deposited, I like to pour it quietly in, so that it may fall to the bottom. The deposit is then clearly shown at the juncture of the two fluids.

Alkaline urine should be accurately neutralized by acetic acid, and should pus be present, it should be allowed to stand, and then be filtered. (However, the rennet semi-gelatinizes pus, so that it is not of very great consequence.) This plan should be adopted in all cases where the urine is turbid, from phosphates, pus, mucus, or extraneous matter.

The chief advantages of the employment of rennet are-

1st. Saving of much time.

2nd. Increase of the deposit.

3rd. The deposit is nearly free from phosphates.

4th. It is nearly free from smell.

The rennet I use is prepared in this way:-Take the fourth stomach of a calf as soon as killed, and scour it well inside and out with salt, so as to remove the curd. Let it drain a few hours. Place it in a wide-mouthed jar, and sprinkle a handful of salt upon it. In a short time the juice will exude, and dissolve the salt. Take this and filter through bibulous paper place it in a bottle, and use as required. That left in the jar will continne to vield a fluid for some time; ntherwise some salt and a small quantity of warm water should be poured over it, and allowed to stand a day. Then filter the juice. The stomach may also be filled with salt and sewn up, or it can be stretched on a skin to dry. In the latter cases pour warm water upon it, allowing it to stand some hours, adding salt to help to preserve it. The more concentrated the juice is the better.

Rennet, already salted, may be obtained of almost any butcher.

Wellington-street, London-bridge, September, 1859

ON A

\section{CASE OF REFLEX PARAPLEGIA IN WHICH STRYCHNIA WAS SUCCESSFULLY EXHIBITED.}

BY WILLIAM MOORE, M.B., M.R.I.A.

PRYSTCIAN TO THE HOSPITAL FOR DISEASES OP CHILDREN, ENC, DTBIIN,

As the physiology, pathology, and treatment of cerebrosinal and paralytic affections generally may be said of late to liave engaged a more than usual share of attention, the details of the following case (an opportunity of treating which was lindly afforded me by Dr. Kirlipatrick) may not prove devoid of some interest:-
George $\mathrm{M}-$, aged thirty, a porter in a large furniture establishment in this city, was admitted into the hospital of the North Dublin Union Workhouse. He states that abont six weeks ago he was drenched to the skin, and remained in his wet clothes under heavy rain for hours-in fact, from midday until one o'clock in the morning. From the history of his case, it is evident he went about for ten days after with a feel. ing of malaise, complaining of no special ailment; during which time he confesses to have taken whisky freely. On the morn. ing of the third day after this wetting, on awaking, he was unable to turn in bed, and complained of pain from his armpits downwards.

I first saw this patient on the 29th of August, when, with difficulty, he was placed in the prostrate position. I examined the spinal column, and failed to detect any evidence of organic disease. He had tenderness-not actual pain-on being tapped over the lumbar region, where the muscles were lax and flabby, he had perfect use of his arms and upper extremities, and, acting from a fixed point, could thus turn his whole body. The pulse was natural, and the tongue clean. In the early stage of the attack he passed his urine in small quantity, and with some uneasiness; that has passed off, and he now micturates freely urine of a healthy character. In the absence of galvanism with wet sponges, I desired him to be extensively "dry cupped" over the dorsal and lumbar region.

On the following day, August 30th, there was no change of any note. The patient had been very efficiently dry cupped as desired. I now prescribed one grain of strychnia, and a few drops of rectified spirits, with bread sufficient to form sixteen pills, of which he was to take one three times in the day.

On the afternoon of the 31 st, the man complained of twitchings and startings in the back and muscles of the lower extremities generally; can turn himself in bed. To continue the pills as before.

Sept. 1st. - The patient got out of bed without any assistance and walked down the ward. No doubt he occasionally faltered and was unsteady, but he never lost the perpendicular, and returned to bed independent of any support. He complains very much of the startings, particularly across the lumbar region, which, he says, awoke him ont of sleep, and he is afraid to cough or take a deep inspiration lest he might induce them. The pills to be repeated.

On the 2nd of September this man turned out of bed at once, walked steadily, and, I may add, briskly down the ward. As he is so much improved to-day, and complains of the jerk. ings in his back, I omitted one of the pills.

His recovery has since been confirmed in every particular, and, on the 6 th, the man was sent out of hospital.

I think this is an instance of what might be termed "peripheral or circumferential reflex paralysis," as it had its origin evidently from standiag in wet and cold for so many hours, there being no lesion of the bladder, kidneys, or other viscera to account for its reflection from any of them. I find a somewhat similar case related by Dr. Graves ("Clinical Medicine," p. 503), where a man was seized with paralysis of the lower extremities by exposing his feet to cold and wet while baling out water in a quarry. Speaking of the prognosis of such cases, ${ }^{*}$ Dr. Brown-Séquard says its gravity depends in a great measure on the severity of the disease which induced it. If it does not arise from organic disease or other cause which is in itself generally fatal, it will often admit of cure, and that, perhaps, very rapidly. The cases where recovery is so decided and rapid are very rare. I find Dr. Watson mentions a case of paraplegia from exposure to cold, in which complete recovery was effected in two days.

G. M-_'s case goes to show what a valuable agent we possess in strychnia in paralytic affections, where we have no reason to suspect the presence of myelitis or other organic cerebro-spinal disease. On the treatment of such cases as the above, $I$ am again tempted to quote Dr. Brown-Séquard, who says, if strychnia be administered in the reflex form it may be advan. tageous; but in cases of paraplegia consequent upon congestion or actual inflammation of the cord, if you give strychnia you will always aggravate the affection.

In the above case, after a careful examination, I felt satisfitc? there was no organic lesion present, and accordingly I pre. scribed strychnia, having first stimulated the muscles by "dry cupping." I should have preferred the use of galvanism with wet sponges, but, for reasons which it is needless to mention, this was not convenient. The result realized my most san guine expectations, marked recovery having taken place on the second day. I may add that the "twitchings" were exclu 